\title{
Long-acting reversible contraception in adolescents: a systematic review and meta-analysis
}

\author{
Justin T. Diedrich, MD, MSCI; MAJ David A. Klein, MD, MPH; Jeffrey F. Peipert, MD, PhD
}

\begin{abstract}
BACKGROUND: Among adolescent pregnancies, 75\% are unintended. Greater use of highly-effective contraception can reduce unintended pregnancy. Although multiple studies discuss adolescent contraceptive use, there is no consensus regarding the use of long-acting reversible contraception as a first-line contraception option.
\end{abstract}

OBJECTIVE: We performed a systematic review of the medical literature to assess the continuation of long-acting reversible contraceptives among adolescents.

STUDY DESIGN: Ovid-MEDLINE, Cochrane databases, and Embase databases were searched using key words relevant to the provision of long-acting contraception to adolescents. Articles published from January 2002 through August 2016 were selected for inclusion based on specific key word searches and detailed review of bibliographies. For inclusion, articles must have provided data on method continuation, effectiveness, or satisfaction of at least 1 long-acting reversible contraceptive method in participants $<25$ years of age. Duration of follow-up had to be $\geq 6$ months. Long-acting reversible contraceptive methods included intrauterine devices and the etonogestrel implant. Only studies in the English language were included. Guidelines, systematic reviews, and clinical reviews were examined for additional citations and relevant points for discussion. Of 1677 articles initially identified, 90 were selected for full review. Of these, 12 articles met criteria for inclusion. All studies selected for full review were extracted by multiple reviewers; inclusion was determined by consensus among authors. For studies with similar outcomes, forest plots of combined effect estimates were created using the random effects model. The meta-analysis of observational studies in epidemiology guidelines were followed. Primary outcomes measured were continuation of method at 12 months, and expulsion rates for intrauterine devices.

RESULTS: This review included 12 studies, including 6 retrospective cohort studies, 5 prospective observational studies, and 1 randomized controlled trial. The 12 studies included 4886 women age $<25$ years: 4131 intrauterine device users and 755 implant users. The 12-month continuation of any long-acting reversible contraceptive device was $84.0 \%$ (95\% confidence interval, $79.0-89.0 \%$ ). Intrauterine device continuation was $74.0 \%$ (95\% confidence interval, $61.0-87.0 \%)$ and implant continuation was $84 \%$ (95\% confidence interval, 77.0-91.0\%). Among postpartum adolescents, the 12-month long-acting reversible contraceptive continuation rate was $84.0 \%$ (95\% confidence interval, $71.0-97.0 \%$ ). The pooled intrauterine device expulsion rate was 8.0\% (95\% confidence interval, 4.0-11.0\%). CONCLUSION: Adolescents and young women have high 12-month continuation of long-acting reversible contraceptive methods. Intrauterine devices and implants should be offered to all adolescents as first-line contraceptive options.

Key words: adolescents, birth control, contraception, implant, intrauterine device, long-acting reversible contraception, meta-analysis, systematic review

\section{Introduction}

Almost 1 in 5 female adolescents and young women will give birth before age
20 years. ${ }^{1}$ Of the approximately 574,000 adolescent pregnancies that occur each year in the United States, $75 \%$ are

From the Department of Obstetrics and Gynecology, University of California, Riverside, Riverside, CA (Dr Diedrich); Departments of Family Medicine and Pediatrics, Uniformed Services University of the Health Sciences, Bethesda, MD (Dr Klein); and Department of Obstetrics and Gynecology, Indiana University School of Medicine, Indianapolis, IN (Dr Peipert).

Received Oct. 25, 2016; revised Nov. 24, 2016; accepted Dec. 19, 2016.

Disclosures: Dr Diedrich is a Nexplanon trainer for Merck, a contraceptive trainer for Upstream USA, and serves on the board of directors of URGE. Dr Peipert receives research support from Teva, Bayer Healthcare Pharmaceuticals, and Merck \& Co Inc, and serves on advisory boards for Teva

Pharmaceuticals and Perrigo. Dr Klein reports no conflicts of interest. The opinions and assertions contained herein are the private views of the authors and are not to be construed as official or as reflecting the views of the US Air Force, the US Army, or the US Military at large.

Corresponding author: Justin T. Diedrich, MD, MSCl. diedrich@ucr.edu

0002-9378/\$36.00 • ๑ 2016 Elsevier Inc. All rights reserved. • http://dx.doi.org/10.1016/j.ajog.2016.12.024

unintended. ${ }^{2}$ Although the United States has experienced a recent decline in teen pregnancy, ${ }^{3}$ the rate remains higher than the rates in many other comparable developed nations. ${ }^{4}$ Rates of unintended pregnancy in young women in poverty have increased while rates in more affluent women have declined. Racial and ethnic disparities also exist. The pregnancy rates among black and Latina teens are over twice that of white teens. ${ }^{1}$ Adolescents who become pregnant, and especially those pregnant again within 1 year of the previous pregnancy, are more likely to subsequently experience serious negative educational, economic, health, and social events than are adolescent females of the same age, race, and 
ethnicity who did not become pregnant. ${ }^{5}$ Inconsistent use of contraceptives, use of less-effective methods, and nonuse of contraceptives contribute to the high rate of unintended pregnancy among US adolescents. $^{2}$

Greater use of highly effective contraception can reduce unintended pregnancy rates in this at-risk population. Long-acting reversible contraceptive (LARC) methods include intrauterine devices (IUDs) and the etonogestrel (ENG) subdermal implant. There are 2 general groups of IUDs commercially available in the United States: hormonal and nonhormonal. The primary mechanism of the levonorgestrel-containing IUD (LNGIUD) is the release of the progestin levonorgestrel, which thickens cervical mucus, thereby preventing fertilization. The primary mechanism of the nonhormonal copper-containing IUD (Cu-IUD) is the release of copper ions that inhibit sperm function, preventing fertilization. The reversible method of contraception most commonly used by US women is the oral contraceptive pill. ${ }^{6}$ The failure rate of combined hormonal contraceptive methods (oral contraceptive pill, ring, or patch) is $>20$-fold higher than that of LARC methods. ${ }^{7}$ The safety of LARC methods is well-established and has led to their endorsement as first-line contraceptive methods by the American Congress of Obstetricians and Gynecologists $(\mathrm{ACOG})^{8}$ and the American Academy of Pediatrics (AAP). ${ }^{9}$ In the Selected Practice Recommendations for Contraceptive Use, the Centers for Disease Control and Prevention (CDC) acknowledge that LARCs are the most effective reversible methods and are appropriate for adolescents and nulliparous women. ${ }^{10-12}$ Although multiple studies discuss continuation of LARC methods in the adolescent population, there is no consensus of continuation rates for IUDs and implants among adolescents and young women. The objective of this systematic review is to provide an assessment of the findings of the medical literature of the use of LARC methods in young women age $<25$ years. Our hypothesis

\section{FIGURE 1}

\section{Selection of included studies in systematic review}

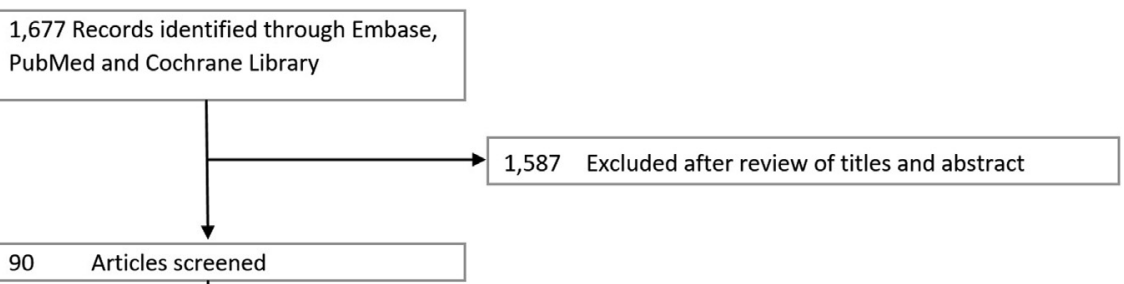

$90 \quad$ Articles screened

78 Excluded after review of full text:

Outcome of interest not reported

Adolescent data not specified

Duplicate studies

Follow-up less than $70 \%$

Cross-sectional data only

12 Included for analysis

Studies included in systematic review of adolescent use of long-acting reversible contraceptives.

Diedrich. LARCs and adolescents. Am J Obstet Gynecol 2017.

was that continuation rates for adolescents using the IUD or implant are high $(>75 \%)$ at 1 year from initiation.

\section{Materials and Methods}

\section{Search strategies and data sources}

We included both randomized controlled trials (RCT) and observational trials in our review. Meta-analysis of observational studies in epidemiology (MOOSE) guidelines were followed. ${ }^{13} \mathrm{~A}$ literature search was performed of the Ovid-MEDLINE, Cochrane databases, and Embase databases using key words relevant to the provision of long-acting contraception to adolescents. Because the goal was to look at contemporary LARC methods, the search was limited to articles published in 2002 or later. The search was limited to English-language articles. The full search terms and strategy are shown in online supplementary material.

\section{Inclusion and exclusion criteria}

To be included in our final analysis, articles must have reported data on continuation of at least 1 LARC method among participants with at least 6 months of follow-up. While the primary outcome was continuation at 12 months, studies were included that have 6-month continuation as a secondary outcome when assessing expulsion. Included studies must have provided actual continuation of participants, not estimated continuation. "Adolescent" is not consistently defined by specific ages in the medical literature, therefore we included women $\leq 24$ years of age. When a study included age groups extending $>24$ years of age, the published article must have stratified the results by age group and must have included at least 1 cohort of at least 20 participants exclusively $\leq 24$ years of age. When data were not reported for such a cohort, the study was excluded. In addition, studies with $>30 \%$ loss to 12 -month follow-up were excluded. Studies were also excluded if they described LARC among special populations of adolescents (eg, those with chronic disease such as HIV). Studies examining postabortion and postpartum adolescents were included. Two investigators (J.T.D. and D.A.K.) independently assessed titles and abstracts for inclusion. Articles that both of them deemed to meet inclusion criteria were included. In cases of disagreement, the senior author (J.F.P.) determined whether inclusion criteria were met.

\section{Data extraction}

Data were extracted by 2 investigators (J.T.D. and D.A.K.) for all included 


\section{TABLE 1}

Included studies evaluating use of long-acting reversible contraception among adolescent patients

\begin{tabular}{|c|c|c|c|c|c|c|c|c|c|c|c|}
\hline Author & Year & Study type & $\begin{array}{l}\text { Age } \\
\text { range, y }\end{array}$ & $\mathbf{n}$ & LARC & $\begin{array}{l}\text { Follow-up, } \\
\text { mo }\end{array}$ & Outcome & Insertion timing & Country & Nulliparous & Attrition \\
\hline Godfrey et $\mathrm{al}^{18}$ & 2010 & RCT & $14-18$ & 23 & $\begin{array}{l}\text { Cu-IUD } \\
\text { LNG-IUD }\end{array}$ & 6 & $\begin{array}{l}6 \text { mo Continuation } \\
\text { Expulsion }\end{array}$ & Interval & US & $52 \%$ & $2 \%$ \\
\hline Guazzelli et al $^{19}$ & 2010 & $\begin{array}{l}\text { Prospective } \\
\text { cohort }\end{array}$ & $<20$ & 44 & Implant & 12 & 12 mo Continuation & Postpartum & Brazil & 0 & $6 \%$ \\
\hline Alton et $\mathrm{al}^{15}$ & 2012 & $\begin{array}{l}\text { Retrospective } \\
\text { cohort }\end{array}$ & $11-21$ & 233 & $\begin{array}{l}\text { Cu-IUD } \\
\text { LNG-IUD }\end{array}$ & 96 & 12 mo Continuation & Interval & US & $30 \%$ & NR \\
\hline Rosenstock et al ${ }^{20}$ & 2012 & $\begin{array}{l}\text { Prospective } \\
\text { cohort }\end{array}$ & $14-19$ & 763 & $\begin{array}{l}\text { Cu-IUD } \\
\text { LNG-IUD } \\
\text { Implant }\end{array}$ & 12 & 12 mo Continuation & $\begin{array}{l}\text { Interval, postpartum, } \\
\text { postabortion }\end{array}$ & US & $77 \%$ & $6 \%$ \\
\hline Teal and Sheeder ${ }^{21}$ & 2012 & $\begin{array}{l}\text { Retrospective } \\
\text { cohort }\end{array}$ & $14-23$ & 136 & $\begin{array}{l}\text { Cu-IUD } \\
\text { LNG-IUD }\end{array}$ & 12 & $\begin{array}{l}12 \text { mo Continuation } \\
\text { Expulsion }\end{array}$ & Postpartum & US & 0 & $14 \%$ \\
\hline Tocce et $\mathrm{al}^{24}$ & 2012 & $\begin{array}{l}\text { Prospective } \\
\text { cohort }\end{array}$ & $13-23$ & 171 & Implant & 12 & $\begin{array}{l}12 \text { mo Continuation } \\
6 \text { mo Continuation }\end{array}$ & Postpartum & US & 0 & $5 \%$ \\
\hline Garbers et al $^{17}$ & 2013 & $\begin{array}{l}\text { Retrospective } \\
\text { cohort }\end{array}$ & $14-19$ & 73 & Cu-IUD & 6 & 6 mo Continuation & NR & US & NR & $15 \%$ \\
\hline Aoun et al ${ }^{16}$ & 2014 & $\begin{array}{l}\text { Retrospective } \\
\text { cohort }\end{array}$ & $13-24$ & 999 & $\begin{array}{l}\text { CU-IUD } \\
\text { LNG-IUD }\end{array}$ & 36 & $\begin{array}{l}12 \text { mo Continuation } \\
\text { Expulsion }\end{array}$ & NR & US & $16 \%$ & $13 \%$ \\
\hline Cohen et $\mathrm{al}^{22}$ & 2016 & $\begin{array}{l}\text { Prospective } \\
\text { cohort }\end{array}$ & $13-22$ & 244 & $\begin{array}{l}\text { Cu-IUD } \\
\text { LNG-IUD } \\
\text { Implant }\end{array}$ & 12 & $\begin{array}{l}12 \text { mo Continuation } \\
6 \text { mo Continuation } \\
\text { Expulsion }\end{array}$ & Postpartum & US & 0 & $17 \%$ \\
\hline Teal et $\mathrm{al}^{23}$ & 2015 & $\begin{array}{l}\text { Retrospective } \\
\text { cohort }\end{array}$ & $13-24$ & 1146 & $\begin{array}{l}\text { Cu-IUD } \\
\text { LNG-IUD }\end{array}$ & 6 & $\begin{array}{l}6 \text { mo Continuation } \\
\text { Expulsion }\end{array}$ & Interval & US & $59 \%$ & $30 \%$ \\
\hline Berlan et al $^{25}$ & 2016 & $\begin{array}{l}\text { Retrospective } \\
\text { cohort }\end{array}$ & $12-22$ & 750 & Implant & 12 & 12 mo Continuation & Interval & US & $85 \%$ & NR \\
\hline Gemzell-Danielsson et $\mathrm{al}^{26}$ & 2016 & $\begin{array}{l}\text { Prospective } \\
\text { cohort }\end{array}$ & $12-17$ & 304 & LNG-IUD & 12 & $\begin{array}{l}12 \text { mo Continuation } \\
\mathrm{AE}\end{array}$ & Interval & Multi & $98 \%$ & $1 \%$ \\
\hline
\end{tabular}

$A E$, adverse events; $C$, copper-containing; IUD, intrauterine device; $L A R C$, long-acting reversible contraceptive; $L N G$, levonorgestrel-containing; NR, not reported; $R C T$, randomized controlled trial.

Diedrich. LARCs and adolescents. Am J Obstet Gynecol 2017. 
studies. Data extracted included the study methodology, number of participants, age range, type of LARC used, and insertion setting (postpartum, postabortion, or interval). Interval insertion was defined as not during the initial postpartum period. Additional data extracted were the time of followup, primary and secondary outcomes measured, and attrition. We noted the number (and ages) of adolescents included, and their specific subgroup outcomes. We also recorded the number of reported IUD expulsions.

\section{Assessment of risk of bias}

Risk of bias was assessed using the checklist described by Downs and Black. ${ }^{14}$ Studies received points for their low risks of bias in several categories: reporting, external validity, bias, and confounding. There were a total of 27 points assigned in the following categories: reporting (10 points possible), external validity ( 3 points possible), bias ( 7 points possible), and confounding ( 7 points possible). Studies were grouped according to their score, with high scores indicating lower risk bias: excellent (2527), good (19-24), fair (14-18), and poor $(<14)$.

\section{Data synthesis}

The proportion of women continuing LARC methods were pooled for continuation rates of 6 and 12 months using a random effects model. Individual estimates were weighted by their SE. The same technique was used for proportions of women with expulsion of their IUDs. Heterogeneity of studies was assessed by using $\mathrm{I}^{2}$ and further characterized using Egger test of publication bias.

\section{Results}

\section{Study selection}

Using our search strategy, 1677 citations were identified. From these titles and abstracts, 90 articles appeared to meet our inclusion criteria. Of these, 39 were excluded because they did not provide data on the primary endpoint; 24 were excluded because the primary endpoint was not stated for the adolescent subgroup; 8 studies were separate analyses of

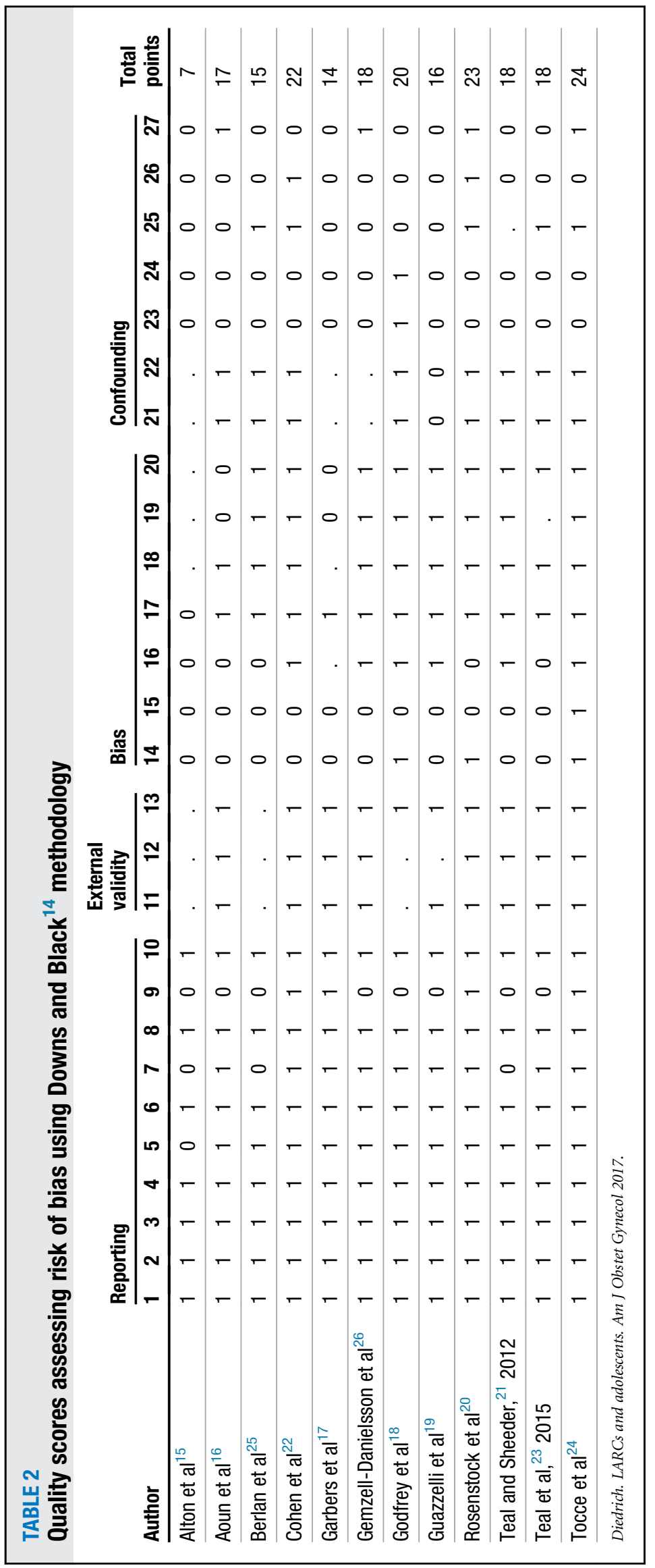




\section{FIGURE 2}

\section{Pooled 12-month continuation rates of long-acting reversible contraceptive (LARC) methods among adolescents}

\section{Pooled 12-month LARC Continuation Rates}

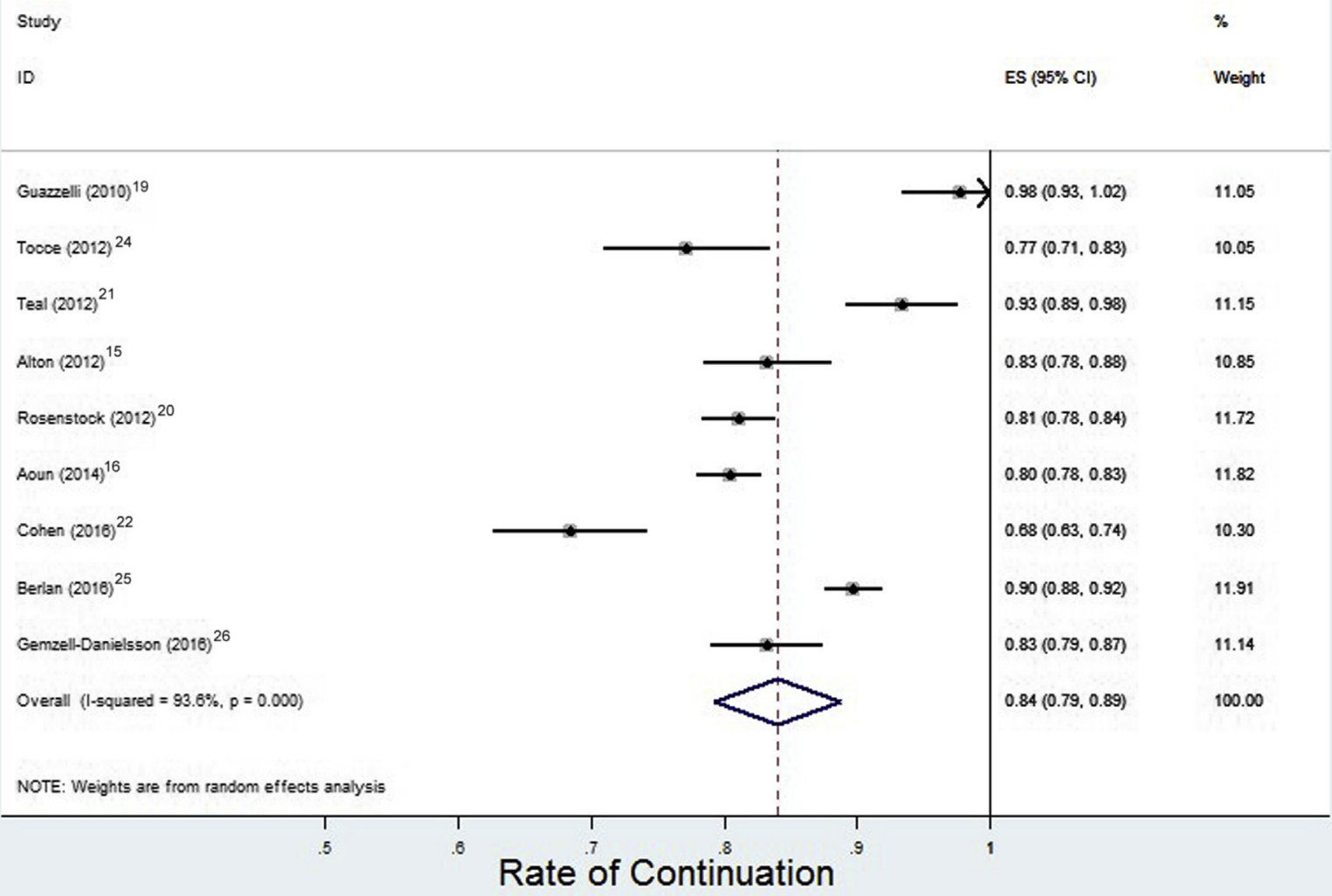

$I D$, identification of study; $E S$, effect size; $C l$, confidence interval; $L A R C$, long-acting reversible contraceptive.

Diedrich. LARCs and adolescents. Am J Obstet Gynecol 2017.

other included studies; 4 were excluded because follow-up was $<70 \%$; and an additional 3 studies were excluded because they were cross-sectional studies. After exclusions, 12 articles that met all criteria and were included for analysis. ${ }^{15-26}$ Figure 1 shows the selection of included articles.

\section{Study characteristics}

Characteristics of individual studies are presented in Table 1. A total of 4886 adolescent and young adult women $(<25$ years of age $)$ were included from all studies. Sample sizes from the included studies ranged from 23-1146. Among the included studies, 755 subjects used the subdermal implant and 4131 used the IUD. There were 8 studies that included the $\mathrm{Cu}$ IUD, ${ }^{15-18,20-23} 9$ studies that included the LNG-IUD, ${ }^{15-18,20-23,26}$ and 4 studies that included the ENG implant. ${ }^{19,22,25,27}$ Many of the studies compared LARC methods. Comparisons between Cu-IUD and LNG-IUD were performed in 8 studies ${ }^{15-18,20-23}$; 2 studies included cohorts of both IUD and the ENG implant users. ${ }^{20,22}$ Three studies included only data for 6 months of continuation, ${ }^{17,18,23}$ which account for a total of $1242 \mathrm{pa}-$ tients. LARCs were placed postpartum in 4 studies, ${ }^{19,21,22,24}$ and interval placement in 3 studies. ${ }^{15,18,23}$ There were 2 studies ${ }^{16,17}$ that did not specify the timing of LARC placement. One study $^{20}$ allowed placement postpartum, postabortion, or interval.

Of the 12 studies, 1 study was a RCT, ${ }^{18}$ and the remaining 11 were observational studies. Five studies were prospective cohort studies ${ }^{19-21,26,27}$ and 6 studies were retrospective cohort studies. ${ }^{15-17,21,23,25}$ Overall, approximately $34 \%$ of adolescents in the included studies were nulliparous. Follow-up ranged between 6-96 months, with median follow-up of 12 months. Median follow-up was the same for both prospective and retrospective studies. Ten of the included studies were performed in the United States, ${ }^{15-18,20-23,25-27} \quad 1$ study was 


\section{FIGURE 3}

\section{Pooled 12-month continuation rates of intrauterine devices (IUD) among adolescents}

\section{Pooled 12-month IUD Continuation Rates}

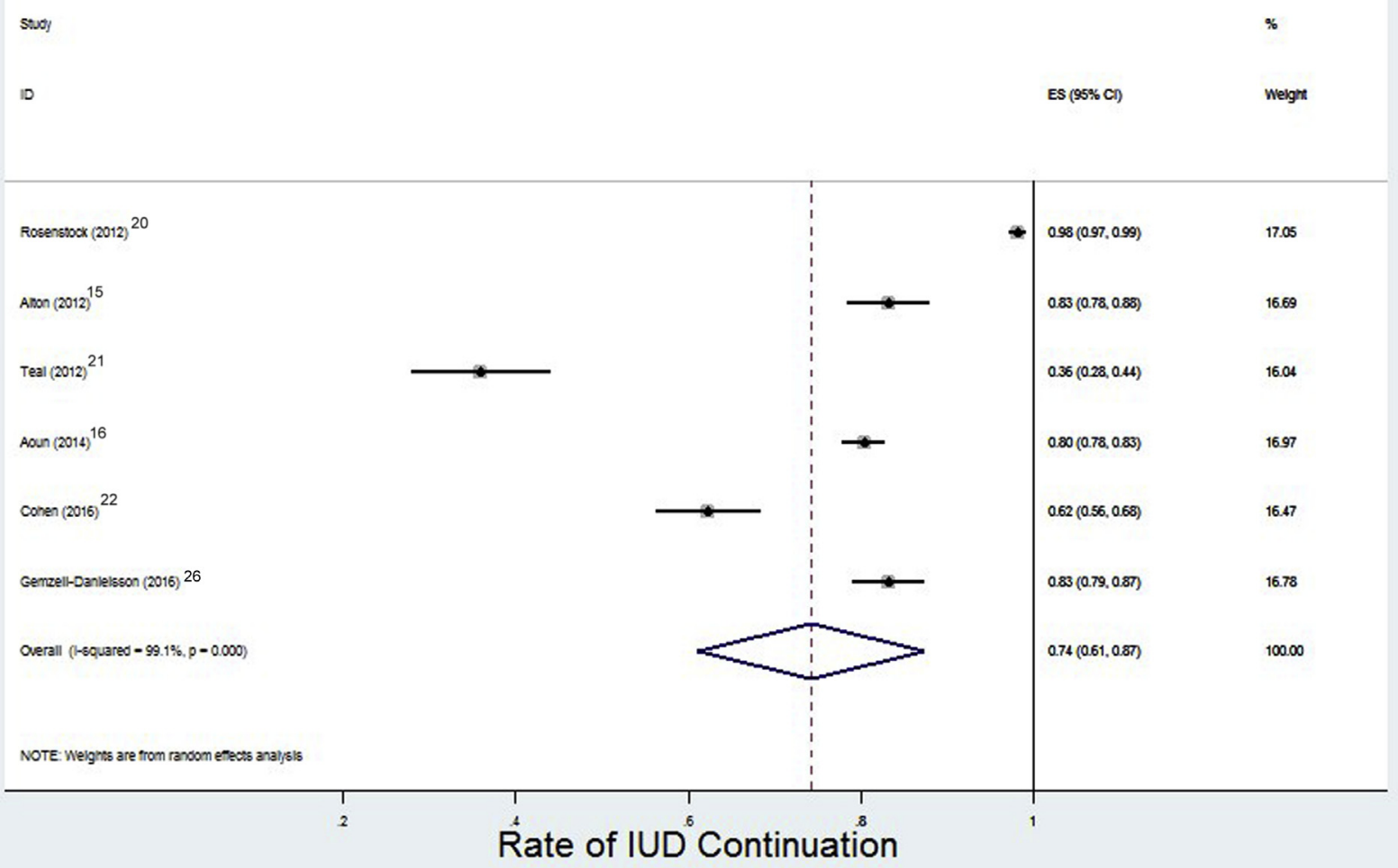

$I D$, identification of study; $E S$, effect size; $C l$, confidence interval; IUD, intrauterine device.

Diedrich. LARCs and adolescents. Am J Obstet Gynecol 2017.

performed in Brazil, ${ }^{19}$ and 1 study was a multinational study. ${ }^{26}$

\section{Randomized controlled trial}

Godfrey and colleagues ${ }^{18}$ performed a pilot RCT that randomized 23 adolescents and young women between age 13-18 years to either Cu-IUD $(\mathrm{n}=11)$ or LNG-IUD $(\mathrm{n}=12)$. Subjects had an interval IUD placement or placement at least 7 weeks postpartum. Continuation at 6 months was $75 \%$ for LNG-IUD and $45 \%$ for Cu-IUD $(P=.15)$. Despite high discontinuation, the majority of subjects reported being satisfied with their IUD at 6 months (70\% of LNG-IUD and $80 \%$ of Cu-IUD users). Two Cu-IUD expulsions, but no LNG-IUD expulsions, were reported.

\section{Observational studies}

In 2012, Rosenstock and colleagues ${ }^{20}$ published a subanalysis of the adolescents participating in the Contraceptive CHOICE Project. CHOICE was a prospective observational study of women in the St Louis, MO, area who were provided with no-cost contraception for 2-3 years. All participants received tierbased contraceptive counseling and their method of choice. Of the 763 adolescents and young women (14-19 years) who started a LARC method at baseline, continuation at 12 months was $81 \%$ among LNG-IUD users, 76\% among $\mathrm{Cu}-\mathrm{IUD}$ users, and $82 \%$ among implant users. By 12 months, $<6 \%$ of adolescent participants had been lost to follow-up. Expulsion of IUDs was not reported in the article. However, another article from the same study population estimated the risk of expulsion at 10.5 per 100 IUD users per 12 months (95\% confidence interval [CI], 8.0-13.5) among women $<20$ years of age. ${ }^{28}$

Guazzelli and colleagues ${ }^{19}$ included 44 adolescents who presented $<6$ months postpartum for LARC at a clinic in São Paolo, Brazil. The cohort had an average age of 17 years; $91 \%$ had 1 child and the remainder had $\geq 2$. All women included had a subdermal implant placed and were followed prospectively for 1 year; $6 \%$ were lost to follow-up. Continuation was $94 \%$ at 12 months, and the rate of amenorrhea was $38 \%$ by 12 months. Another prospective study was performed by Cohen and colleagues. ${ }^{22}$ Adolescents and young women (ages 13-22 years) who chose postplacental IUDs 


\section{FIGURE 4}

\section{Pooled 12-month continuation rates of etonogestrel (ENG) subdermal implants among adolescents}

\section{Pooled 12-month ENG Continuation Rates}

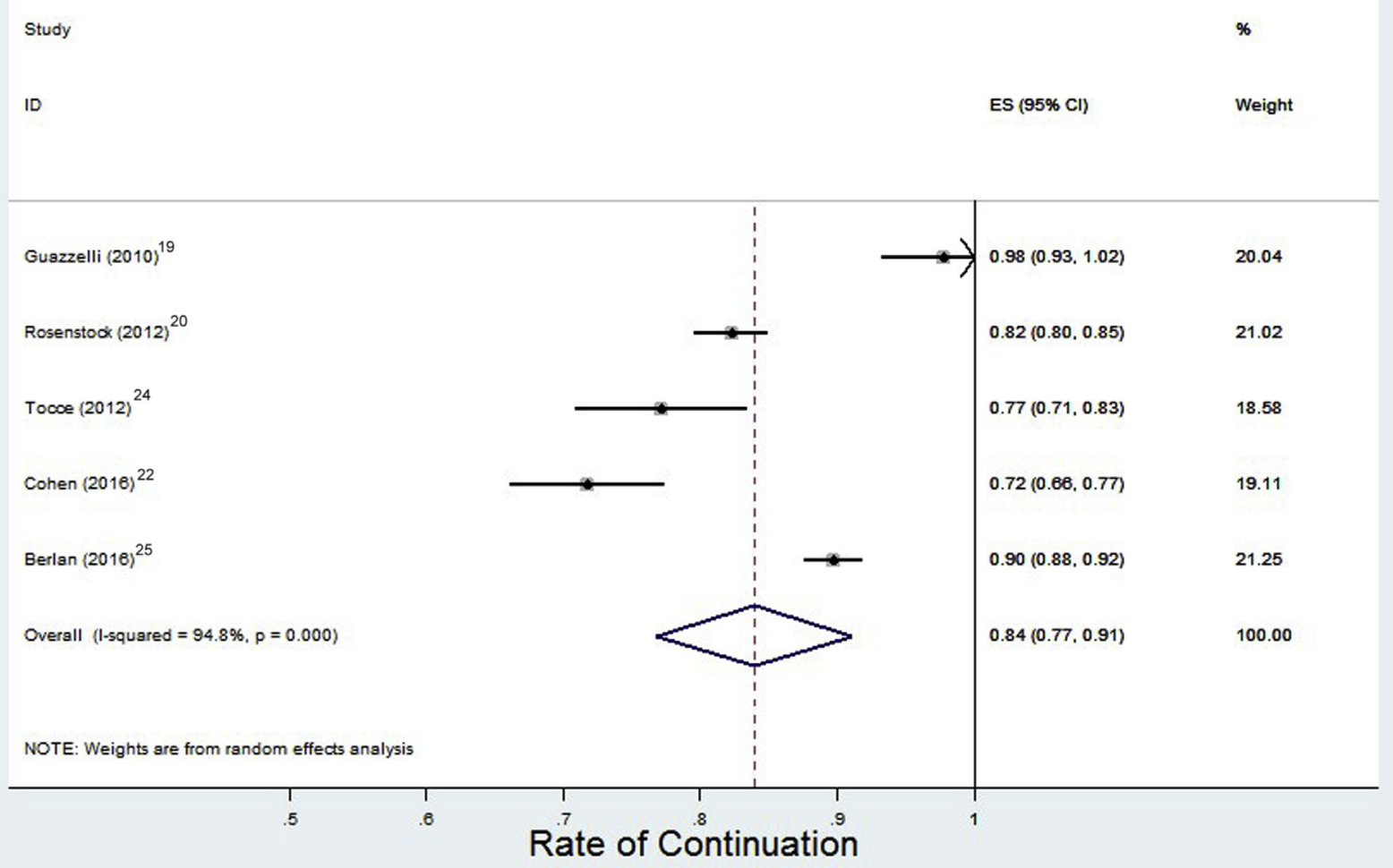

$I D$, identification of study; $E S$, effect size; $C l$, confidence interval; $E N G$, etonogestrel subdermal implant.

Diedrich. LARCs and adolescents. Am J Obstet Gynecol 2017.

$(\mathrm{n}=82)$ or subdermal implant $(\mathrm{n}=$ 162) to be placed prior to discharge were included. At 12 months, IUD continuation was $62 \%$ and implant continuation was $72 \%$. The observed IUD expulsion rate reported was $21 \%$.

Tocce and colleagues ${ }^{24}$ performed a prospective cohort study of 171 postpartum adolescents and young women (ages 13-24 years) who had subdermal implant placed prior to discharge. This group was compared to a control group of adolescents who chose any other method. The primary outcomes were contraceptive continuation and repeat pregnancy rates. Continuation of the implant was $97 \%$ at 6 months and $86 \%$ at 12 months. The odds of pregnancy were 8 times higher for those who did not choose immediate postpartum implant (odds ratio, 8.0; 95\% CI, $2.8-23.0$ ) compared to women who did choose insertion.

In a subgroup analysis of a large multinational prospective phase III trial, Gemzell-Danielsson and colleagues ${ }^{26}$ evaluated the use of a new IUD among girls and adolescents (12-17 years of age). The IUD evaluated was a LNG-IUD containing $13.5 \mathrm{mg}$ of levonorgestrel released at a rate of $8 \mu \mathrm{g} / \mathrm{d}$. There were 304 adolescents who had the LNG-IUD inserted, and all were followed up for 12 months. Continuation at 12 months was $83 \%$. There were 10 expulsions (3\%) during 12 months.

In a retrospective cohort study, Alton and colleagues ${ }^{15}$ identified 233 adolescents age $<21$ years who had each received a Cu-IUD $(\mathrm{n}=11)$ or LNG-
IUD $(\mathrm{n}=222)$ during an 8-year period. The IUDs had been placed at a private faculty clinic or at a hospitalbased Title X clinic. Of their study population, $70 \%$ were parous and the median age at insertion was 16 years. At 12 months, continuation was $70 \%$ among the youngest group of adolescents (age $<18$ years) and $89 \%$ among those age 18-21 years. The number of IUD expulsions was not reported.

Teal and Sheeder ${ }^{21}$ performed a retrospective cohort study of parous adolescents and young women (14-23 years of age) who had each received a LNG-IUD or Cu-IUD. The average insertion time was 8 months postpartum (none were placed immediately after placental delivery). Median continuation of IUD use was 14 months; range was not 


\section{Pooled 12-month Postpartum Continuation Rates Among LARC Users}

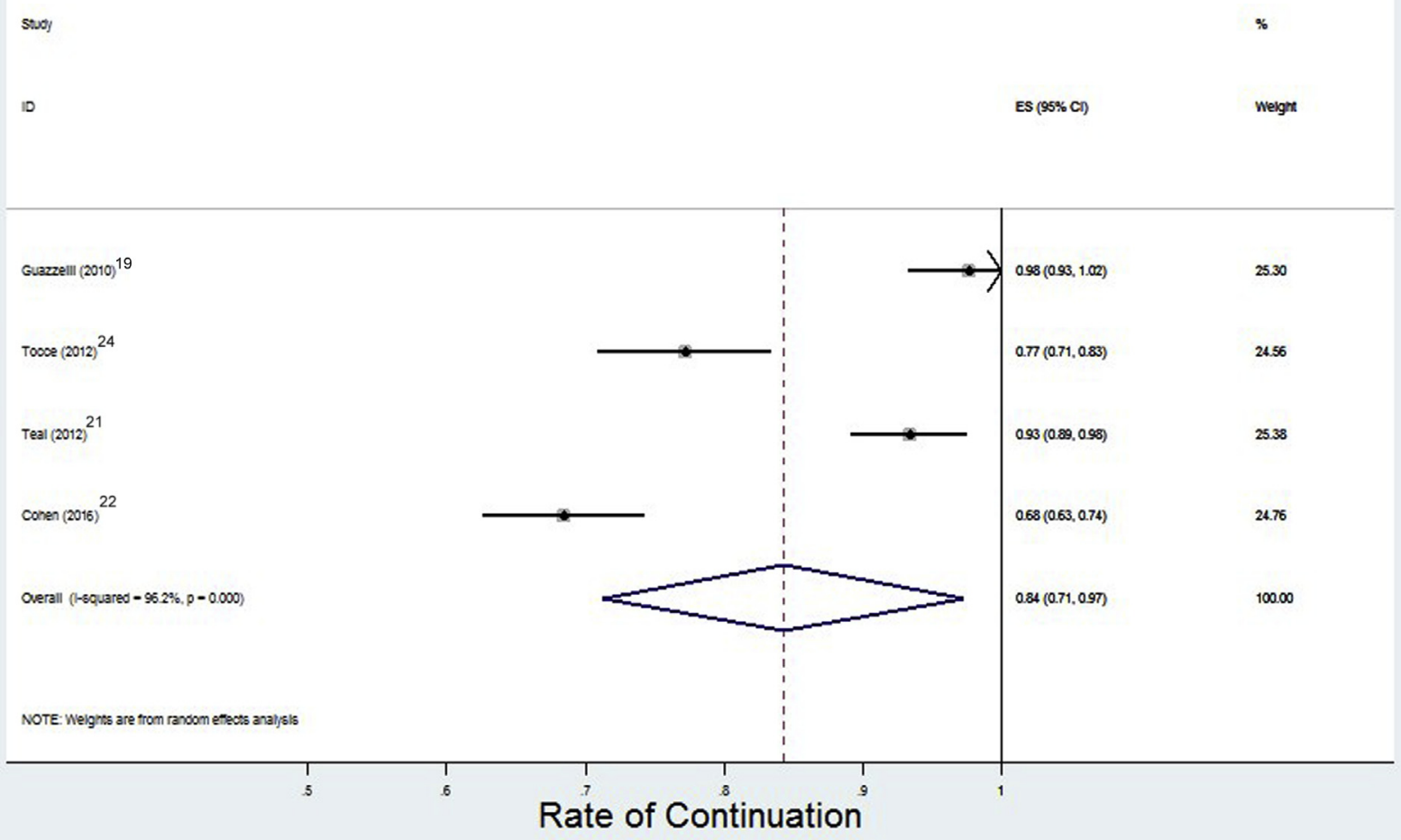

ID, identification of study; $E S$, effect size; $C l$, confidence interval; LARC, long-acting reversible contraceptive.

Diedrich. LARCs and adolescents. Am J Obstet Gynecol 2017.

reported. There was no difference in continuation based on type of IUD. Continuation rates were censored at 60 months. Twelve-month continuation was $55 \%$, and an expulsion rate of $15 \%$ was observed.

Garbers and colleagues ${ }^{17}$ retrospectively reviewed charts of 73 adolescents and young women (ages 14-19 years) who had sought family planning services and had Cu-IUDs placed. According to chart review, 6-month continuation of the Cu-IUD was $88 \%$. IUD expulsions were not reported.

Aoun and colleagues ${ }^{16}$ reviewed charts of 999 adolescents and young women (age 14-24 years) who received a Cu-IUD or LNG-IUD. At the time of insertion, approximately $16 \%$ of participants were nulliparous. At 12 months, continuation was $80 \%$. Only $13 \%$ were lost to follow-up. An expulsion rate of $4 \%$ was observed.

Teal and colleagues ${ }^{23}$ performed a retrospective study of adolescents and young women (13-24 years) who desired an IUD. The goal of this study was to quantify complications and unsuccessful insertions among 1177 who had an attempted IUD placement. Among the 1146 who had a successful insertion, continuation of the IUD was $95 \%$ at 6 months. A $2 \%$ IUD expulsion rate was observed.

A retrospective study was performed by Berlan and colleagues ${ }^{25}$ evaluating 12month continuation of the subdermal implant by adolescents 12-22 years of age. The majority (85\%) were nulliparous. Of 750 patients who had the device placed, only $10 \%$ had discontinued by 12 months (90\% continuation).

\section{Assessment of risk of bias}

The majority of the included studies were of fair or good quality under the Downs and Black methodology. Overall, the average score for reporting results was 9 of 10 points; average scores for external validity were 2.25 of 3 points; average scores for bias were 4 of 7 points; and the average score for confounding was 2.4 of 7 points. See Table 2 for results. The majority of studies had low scores for confounding and bias, which mainly is due to study design. Because only 1 study included was a RCT, there is a higher risk of bias among the 


\section{FIGURE 6}

\section{Pooled intrauterine device (IUD) expulsion rates among adolescents}

\section{Pooled IUD Expulsion Rates}

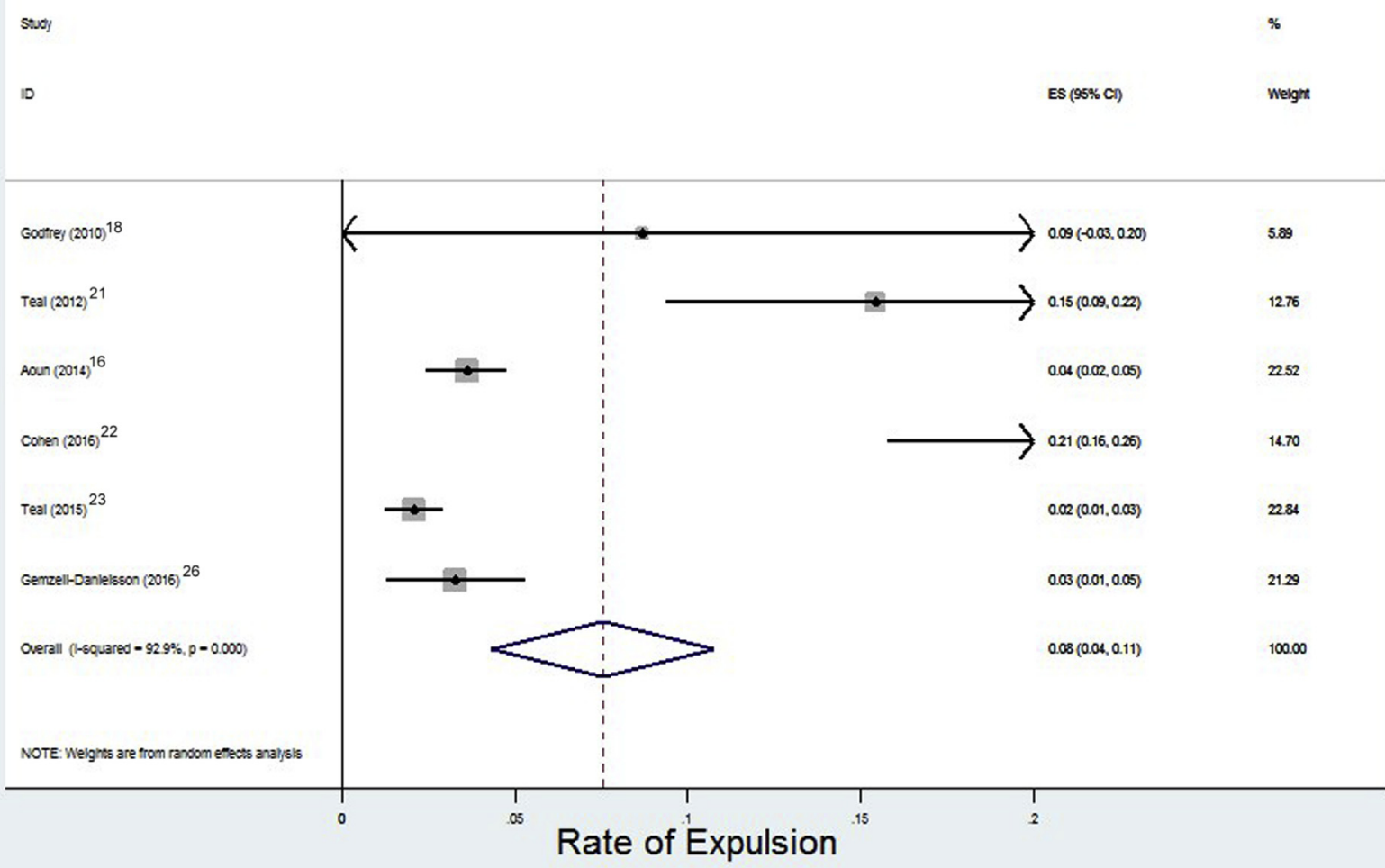

$I D$, identification of study; $E S$, effect size; $C l$, confidence interval; IUD, intrauterine device.

Diedrich. LARCs and adolescents. Am J Obstet Gynecol 2017.

remaining studies. However, 1 advantage of a meta-analysis of observational studies is generalizability and obtaining estimates that are closer to real-life continuation. In practice, women are able to choose their contraceptive method and are not randomly assigned one.

\section{Data synthesis}

The 12-month continuation rates of all LARC methods are provided in Figure 2. Continuation was $84.0 \% \quad(95 \% \mathrm{CI}$, 79.0-89.0\%) for all LARC methods combined. The 12-month continuation rate for IUDs is shown in Figure 3. At 12 months, IUD continuation was $74.0 \%$ (95\% CI, 61.0-87.0\%). The 12-month continuation of ENG implant $84 \%$
(95\% CI, 77.0-91.0\%) is shown in Figure 4. Figure 5 shows 12-month continuation when LARC devices were placed in the postpartum setting. At 12 months, continuation was $84.0 \%$ (95\% CI, 71.0-97.0\%). IUD expulsion rates were pooled in Figure 6, and the overall effect was an expulsion rate of $8.0 \%$ (95\% CI, $4.0-11.0 \%)$. There is significant heterogeneity among studies in all the comparisons above $\left(\mathrm{I}^{2}>92 \%\right.$, $P<.001)$.

\section{Comment}

\section{Main findings}

This systematic review and metaanalysis demonstrates that adolescent continuation of LARC methods is high at 12 months. This includes parous adolescents who had devices placed postpartum as well as nulliparous adolescents. These findings support the recommendations of the $\mathrm{ACOG}^{8}$ as well as the $\mathrm{AAP}^{9}$ which encourages adolescents to consider LARC methods. The CDC also recommends using the methods most effective and medically appropriate for adolescents, including LARC methods. $^{29}$

\section{Strengths and limitations}

One strength of this review is its estimates of continuation among the different studies reviewed. Additionally, the pooled continuation rate includes a large sample. By including observational trials in addition to RCT, we are able to estimate real-world continuation of 
LARCs more accurately (increased generalizability). In actual practice, patients are given a choice of contraceptive method and must choose what they think best fits their priorities and lifestyles. Meta-analyses that include only RCT may actually introduce selection bias by eliminating patient choice of method.

A weakness of this review is the significant heterogeneity among the individual studies examined, which limits the ability to combine continuation outcomes. However, these studies are representative of the variety of settings of LARC provision. When assessing expulsions, there may be significant differences between Cu-IUD and LNG-IUD. Additionally, 1 study ${ }^{26}$ assessed a lowerdose LNG-IUD (13.5 mg reservoir, releasing $8 \mu \mathrm{g} / \mathrm{d}$ ), which should be distinguished from the other LNG-IUDs on the market in the United States. Liletta (Medicines 360) and Mirena (Bayer) contain $52 \mathrm{mg}$ of levonorgestrel and release $20 \mu \mathrm{g} / \mathrm{d}$, Kyleena (Bayer) contains $19.5 \mathrm{mg}$ and releases $9 \mu \mathrm{g} / \mathrm{d}$, and Skyla (Bayer) contains $13 \mathrm{mg}$ and releases $8 \mu \mathrm{g} / \mathrm{d}$. Another limitation may be the inclusion of women up to 25 years of age. This was done intentionally as there is not an agreed-upon definition of the exact years of adolescence. Additionally, not all studies presented data on barriers to removal. When LARC removal is not free or easily attainable for participants, this may not only falsely increase continuation, but in fact be construed as coercive.

\section{Comparison with existing literature}

A Cochrane review by Krashin et $\mathrm{al}^{30}$ and systematic review by Deans and Grimes $^{31}$ and Usinger et $\mathrm{al}^{32}$ showed adolescent continuation of $75-86 \%$ with IUDs. However, these reviews included only RCT, which are different from most prospective observational trials in that patients in observational trials ordinarily are allowed choice of contraceptive method. Observational studies may provide greater generalizability and a more realistic estimate of continuation rates. RCT can lead to an increased discontinuation because the methods are assigned randomly. ${ }^{33,34}$
Another systematic review was performed by Usinger et $\mathrm{al}^{32}$ included RCTs as well as observational studies of women under age 25 who received any type of IUD. They excluded studies that did not compare IUDs to other methods. Our findings are also consistent with a large retrospective study including women in TRICARE. The study includes women of all ages, but in a multivariable analysis found that girls and women 14-19 years of age had higher continuation of LARC methods when compared to women 35-40 years of age: 1.34 (95\% CI, 1.27-1.42). Data were not listed for continuation by age group at 12 months. ${ }^{35}$ Another large retrospective study evaluated insurance claims data of approximately 90,000 women who had an IUD placed from 2002 through 2009. Within this cohort there were 1528 girls and women age 15-19 years who used the LNG-IUD and 307 in the same age group who used the $\mathrm{Cu}$-IUD. Among those 20-24 years of age, 7860 and 2027 used the LNG-IUD and $\mathrm{Cu}-\mathrm{IUD}$, respectively. In the younger cohort the continuation rates for LNG-IUD and Cu-IUD were $88.2 \%$ and $79.8 \%$ at 12 months, respectively. In the cohort aged 20-24 years, continuation was $87.7 \%$ and $84.1 \%$ for the LNGIUD and $\mathrm{Cu}-\mathrm{IUDS}$ at 12 months, respectively. ${ }^{36}$ The main limitation of this type of study is the potential inaccuracy of claims data.

\section{Conclusion with implications}

LARC continuation in adolescents and young women is high. IUDs and implants should be offered to all adolescents as first-line contraceptive options as long as device removal is readily available. Efforts to increase the use of LARC will help decrease the rates of unintended adolescent pregnancy, abortion, and unintended childbearing, and will thereby also help lower the disparities in those rates among different sociodemographic adolescent populations.

\section{ACKNOWLEDGMENT}

The authors would like to acknowledge the work of Ms Wendy Larson, medical librarian at Fort Belvoir Community Hospital, Fort Belvoir, VA, who made this systematic review possible.

\section{REFERENCES}

1. Martinez G, Copen CE, Abma JC. Teenagers in the United States: sexual activity, contraceptive use, and childbearing, 2006-2010 National Survey of Family Growth. Vital Health Stat 23 2011;23:1-35.

2. Finer LB, Zolna MR. Declines in unintended pregnancy in the United States, 2008-2011. N Engl J Med 2016;374:843-52.

3. Hamilton BE, Mathews TJ. Continued declines in teen births in the United States, 2015. NCHS Data Brief 2016;(259):1-8.

4. United Nations. Demographic yearbook 2013. Sixty-four. New York; 2014. Available at: http:// unstats.un.org/unsd/demographic/products/dyb/ dyb2009-2010.htm. Accessed March 2, 2015.

5. Jeha D, Usta I, Ghulmiyyah L, Nassar A. A review of the risks and consequences of adolescent pregnancy. J Neonatal Perinatal Med 2015;8:1-8.

6. Daniels K, Daugherty J, Jones J. Current contraceptive status among women aged 1544: United States, 2011-2013. NCHS Data Brief 2014;(173)::):1-8.

7. Winner B, Peipert JF, Zhao Q, et al. Effectiveness of long-acting reversible contraception. N Engl J Med 2012;366:1998-2007.

8. Committee on Adolescent Health Care LongActing Reversible Contraception Working Group, the American College of Obstetricians and Gynecologists. Adolescents and longacting reversible contraception: implants and intrauterine devices. Committee opinion no. 539. Obstet Gynecol 2012;120:983-8.

9. Committee on Adolescence. Contraception for adolescents. Pediatrics 2014;134:e1244-56. 10. Curtis KM, Tepper NK, Jatlaoui TC, et al. US medical eligibility criteria for contraceptive use, 2016. MMWR Recomm Rep 2016;65:1-103.

11. Curtis KM, Jatlaoui TC, Tepper NK, et al. US selected practice recommendations for contraceptive use, 2016. MMWR Recomm Rep 2016;65:1-66.

12. Gavin L, Moskosky S, Carter M, et al. Providing quality family planning services: recommendations of CDC and the US Office of Population Affairs. MMWR Recomm Rep 2014;63:1-54. 13. Stroup DF, Berlin JA, Morton SC, et al. Metaanalysis of observational studies in epidemiology: a proposal for reporting. Meta-analysis of observational studies in epidemiology (MOOSE) group. JAMA 2000;283:2008-12.

14. Downs SH, Black N. The feasibility of creating a checklist for the assessment of the methodological quality both of randomized and non-randomized studies of health care interventions. J Epidemiol Community Health 1998;52:377-84.

15. Alton TM, Brock GN, Yang D, Wilking DA, Hertweck SP, Loveless MB. Retrospective review of intrauterine device in adolescent and young women. J Pediatr Adolesc Gynecol 2012;25:195-200.

16. Aoun J, Dines VA, Stovall DW, Mete $M$, Nelson CB, Gomez-Lobo V. Effects of age, parity, and device type on complications and 
discontinuation of intrauterine devices. Obstet Gynecol 2014;123:585-92.

17. Garbers S, Haines-Stephan J, Lipton $Y$, Meserve A, Spieler L, Chiasson MA. Continuation of copper-containing intrauterine devices at 6 months. Contraception 2013;87:101-6.

18. Godfrey EM, Memmel LM, Neustadt A, et al. Intrauterine contraception for adolescents aged 14-18 years: a multicenter randomized pilot study of levonorgestrel-releasing intrauterine system compared to the copper T 380A. Contraception 2010;81:123-7.

19. Guazzelli CAF, de Queiroz FT, Barbieri M, Torloni MR, de Araujo FF. Etonogestrel implant in postpartum adolescents: bleeding pattern, efficacy and discontinuation rate. Contraception 2010;82:256-9.

20. Rosenstock JR, Peipert JF, Madden T, Zhao Q, Secura GM. Continuation of reversible contraception in teenagers and young women. Obstet Gynecol 2012;120:1298-305.

21. Teal SB, Sheeder J. IUD use in adolescent mothers: retention, failure and reasons for discontinuation. Contraception 2012;85:270-4.

22. Cohen R, Sheeder J, Arango N, Teal SB, Tocce K. Twelve-month contraceptive continuation and repeat pregnancy among young mothers choosing post-delivery contraceptive implants or postplacental intrauterine devices. Contraception 2016;93:178-83.

23. Teal SB, Romer SE, Goldthwaite LM, Peters MG, Kaplan DW, Sheeder J. Insertion characteristics of intrauterine devices in adolescents and young women: success, ancillary measures, and complications. Am J Obstet Gynecol 2015;213:515.e1-5.

24. Tocce KM, Sheeder JL, Teal SB. Rapid repeat pregnancy in adolescents: do immediate postpartum contraceptive implants make a difference? Am J Obstet Gynecol 2012;206:481. e1-7.

25. Berlan E, Mizraji K, Bonny AE. Twelvemonth discontinuation of etonogestrel implant in an outpatient pediatric setting. Contraception 2016;94:81-6.

26. Gemzell-Danielsson K, Buhling $\mathrm{KJ}$, Dermout SM, Lukkari-Lax E, Montegriffo E, Apter D. A phase III, single-arm study of LNGIUS 8, a low-dose levonorgestrel intrauterine contraceptive system (total content $13.5 \mathrm{mg}$ ) in postmenarcheal adolescents. Contraception 2016;93:507-12.

27. Tocce K, Sheeder J, Python J, Teal SB. Long acting reversible contraception in postpartum adolescents: early initiation of etonogestrel implant is superior to IUDs in the outpatient setting. J Pediatr Adolesc Gynecol 2012;25:59-63.

28. Madden $T$, McNicholas C, Zhao Q, Secura GM, Eisenberg DL, Peipert JF. Association of age and parity with intrauterine device expulsion. Obstet Gynecol 2014;124:718-26.

29. Frieden $T R$, Jaffe HW, Richards $C L$, et al. Providing quality family planning services. Centers for Disease Control and Prevention; MMVR Editorial and Production Staff (Serials) MMWR Editorial Board. Recomm Reports 2014;63(4).
30. Krashin J, Tang JH, Mody S, Lopez LM. Hormonal and intrauterine methods for contraception for women aged 25 years and younger. Cochrane Database Syst Rev 2015;8: CD009805.

31. Deans El, Grimes DA. Intrauterine devices for adolescents: a systematic review. Contraception 2009;79:418-23.

32. Usinger KM, Gola SB, Salas M, Smaldone A. Intrauterine contraception continuation in adolescents and young women: a systematic review. J Pediatr Adolesc Gynecol 2016;29:659-67.

33. Sivin I, el Mahgoub S, McCarthy $T$, et al. Long-term contraception with the levonorgestrel $20 \mathrm{mcg} /$ day ( $\mathrm{LNg} \mathrm{20)}$ and the copper T $380 \mathrm{Ag}$ intrauterine devices: a five-year randomized study. Contraception 1990;42: 361-78.

34. Goldman JA, Dekel A, Reichman J. Immediate postabortion intrauterine contraception in nulliparous adolescents. Isr J Med Sci 1979;15: 522-5.

35. Chiles DP, Roberts TA, Klein DA. Initiation and continuation of long-acting reversible contraception in the United States military healthcare system. Am J Obstet Gynecol 2016;215:328.e1-9.

36. Berenson AB, Tan A, Hirth JM, Wilkinson GS. Complications and continuation of intrauterine device use among commercially insured teenagers. Obstet Gynecol 2013;121: 951-8. 


\section{Supplemental Information \\ Ovid MEDLINE}

1 exp contraception/or exp contraceptive devices/or exp contraceptive agents/

21 and LARC (tw)

3 "long acting reversible contraception".tw.

4 exp intrauterine devices/

5 exp drug implants/ and 1

6 etonogestrel implant: (tw)

7 levonorgestrel intrauterine system: (tw)

82 or 3 or 4 or 5 or 6 or 7

9 limit 8 to English language

10 limit 9 to $y r=$ "2002 -Current"

11 limit 10 to "adolescent (13-18 years)"

12 limit 10 to "young adult (19-24 years)"

1311 or 12

\section{Reviews - Cochrane Database of} Systematic Reviews

1 "long acting reversible contraception".tw.
2 etonogestrel implant: (tw)

3 levonorgestrel intrauterine system: (tw)

4 LARC.mp. [mp=title, short title, abstract, full text, keywords, caption text]

51 or 2 or 3 or 4

6 from 5 keep 2, 9-11, 14-15, 20, $24-25$

7 contracept: (tw)

8 (teen: or adolesce:) (tw)

97 and 8

10 from 9 keep 7, 13, 16, 23, 39, 60

116 or 10

\section{Reviews - Cochrane Central Register of}

Controlled Trials

1 (contraception or contraceptive).mp. $[\mathrm{mp}=$ title, original title, abstract, mesh headings, heading words, keyword]

2 (adolescent or young or nulliparous).mp. [mp=title, original title, abstract, mesh headings, heading words, keyword]
3 (continuation or discontinuation or side effects or compliance or satisfaction).mp. [ $\mathrm{mp}=$ title, original title, abstract, mesh headings, heading words, keyword]

$4 \quad 1$ and 2 and 3

5 limit 4 to $y r=$ "2002 -Current"

\section{Embase -}

(( contraception OR (contraceptive device) OR (contraceptive agent)) AND LARC)

OR

(long acting reversible contraception) OR (intrauterine device)

OR

((contraception OR (contraceptive device) OR (contraceptive agent)) AND (drug implant))

OR

(etonogestrel implant)

OR

(levonorgestrel intrauterine system) 